\title{
Students' Preferences for Medical Schools: A Conjoint Analysis
}

\author{
Mark M. Alipio ${ }^{\mathrm{a}, \mathrm{b}}$ \\ January 2020 \\ ${ }^{a}$ Davao Doctors College, General Malvar St., Davao City 8000, Philippines \\ ${ }^{b}$ University of Southeastern Philippines, Mintal, Davao City 8000, Philippines
}

\begin{abstract}
With the surge of higher education institutions (HEIs) offering the health sciences and medical courses and significant changes in the Philippine education sector, an effective marketing strategy is highly needed. Therefore, HEIs have to compete even more in a very competitive market. The present study aimed to determine the major factors that influence preferences of students who just graduated from senior high school, the relative importance they attach to these factors, and whether there were groups of students for whom different factors were more important. A total of 24,263 prospective students in the health sciences and medical courses from the 125 senior high schools in the Philippines were sampled as respondents. Multi-stage cluster sampling technique was used to recruit the sample. A face to face interview with a set of stimulus cards or through a self-completion questionnaire was used to collect the data and Adaptive Conjoint Analysis (ACA) was performed to analyze students' preferences. Results showed that the four most important determinants of health science and medical HEI choice for students in the Philippines are academic reputation, quality of facilities, job prospects, and campus atmosphere. A cluster analysis failed to uncover any useful clusters, suggesting that the sample was relatively homogeneous in their preferences and the trade-offs that they made in developing those preferences.
\end{abstract}

Keywords: Conjoint Analysis, Education, Health Sciences, Higher Education Institutions, Marketing, Medical Courses, Medical School, Philippines, Preference, Selection, Senior High School

\section{Introduction}

Health sciences and medical education in the Philippines are principally offered and developed by accredited and Commission on Higher Education (CHED) recognized higher education institutions (HEIs). In an attempt to mitigate the scarcity of healthcare workforce, especially the medical doctors in the country, several HEIs opened health sciences and medical programs such as but not limited to Doctor of Medicine, Doctor of Dental Medicine, Nursing, Medical Technology, Pharmacy, Physical Therapy, Occupational Therapy, and Radiologic Technology.

On the other hand, the Philippine tertiary education sector, as in most countries, has experienced a number of significant changes in recent years. The total number of students entering HEIs has fallen and notable changes have been made to the school charges such as increase in tuition and miscellaneous fees. The opening 
of healthcare courses by state universities, government-subsidized HEIs, has drawn tremendous fears to several profit-based private HEIs (Alipio, 2020). Also, the recent adoption of K to 12 education scheme of the country brought drastic changes to the financial capability of the student-paying families in the country (Alipio, 2020).

With the surge of HEIs offering the health sciences and medical courses and significant changes in the country's education sector, an effective marketing strategy is highly needed. Therefore, HEIs have to compete even more in a very competitive market.

The current health sciences and medical HEIs market in the country has three main potential groups, namely, international students, mature-age students, and students who just graduated from senior high school. Each group considers different factors when making their preference of program and school. For example, international students opt to consider the availability of teachers who are multilingual speakers and students who just graduated from senior high school tend to consider job prospects as more important factor. Hence, their preferences need to be explored separately. The present study examined the students who just graduated from senior high school, the group who make up the largest population in HEIs.

Students consider a number of factors when choosing their preference for a particular HEI, including:

- The academic reputation of the HEI (excellent, fair, poor)

- The quality of teaching (above average, average)

- The campus atmosphere (quiet, lively)

- The quality of facilities (above average, average)

- Job prospects

Students might also consider more personal factors, such as:

- Distance from home (including time taken to get to each university)

- Family opinion

- The HEI their friends wish to attend

Whatever the factors that affect students' choice, some factors will be more important than others. Hence, the present study is focused on the determination of the major factors that influence preferences of students who just graduated from senior high school, the relative importance they attach to these factors, and whether there were groups of students for whom different factors were more important. The findings of the study may provide a good foundation for formulating sound marketing strategies that would appeal to prospective health sciences and medical students who just graduated from senior high school. 


\subsection{Conjoint attributes and attributes level}

The conjoint attributes and attributes level were chosen based on the review of the literature and input from members of the all HEIs marketing teams and the deans or heads for student services. Table 1 presents the details of the attributes and attribute levels used in the conjoint analysis.

Table 1. Conjoint attributes and attributes level

\begin{tabular}{ll}
\hline Attribute & Level \\
\hline Academic Reputation & Has an excellent academic reputation \\
& Has a fair academic reputation \\
& Has a poor academic reputation \\
Quality of Teaching & Has above average quality of teaching \\
& Has average quality of teaching \\
Campus Atmosphere & Has a lively campus atmosphere \\
Quality of Facilities & Has a quiet campus atmosphere \\
& Has above average quality of facilities \\
Job Prospects & Has average quality of facilities \\
& Would equip with qualifications that provide average job prospects \\
Distance from Home & Would equip with qualifications that provide above average job prospects \\
& Is close to home (less than $10 \mathrm{~km})$ \\
& Is slightly far from home (10-20 km) \\
& Is very far from home (over $20 \mathrm{~km}$ ) \\
Friends & Is held in good opinion by family \\
Family Opinion & Is a school of which my family holds no opinion \\
& Is held in poor opinion by family \\
& Is where my friends will be going \\
& Is not where my friends will be going \\
\hline
\end{tabular}




\section{Methods}

A total of 24,263 prospective students in the health sciences and medical courses from the 125 senior high schools in the Philippines were sampled as respondents. Multi-stage cluster sampling technique was used to recruit the sample, where the final respondents were randomly selected from a sampling frame given by the schools. All of the participants provided consent to participate in the study.

Conjoint analysis requires respondents to make preference decisions for a variety of 'packages' of attributes. As this can be a complex task, it demands respondents have the choices in front of them. This is usually done through a face to face interview with a set of stimulus cards or through a self-completion questionnaire. Such studies generally only include four or five attributes. In the present study, however, eight attributes were finally included. Therefore, a form of conjoint analysis that was suited to the large number of attributes had to be used. Adaptive Conjoint Analysis (ACA) was chosen as it allows many more attributes to be included. The ACA procedure requires the use of a computer as the procedure "adapts" its future questioning based upon the answers respondents make. Table 1 details the attributes and attribute levels used for the conjoint section of the questionnaire.

The conjoint section of the questionnaire was developed using the ACA software developed by Sawtooth Software (Johnson, 1987; ACA System Manual, 1996). It led the students through four stages of the decision process, namely:

1. Students were asked to rate (on a 7-point scale) how desirable different types of health sciences and medical HEIs were.

2. They were then asked to consider how important each attribute would be in choosing between two HEIs in which all other attributes were the same.

3. Based on the responses to parts one and two, the students were presented with different HEIs to consider. Each question presented two HEIs that were described in terms of combinations of attributes. Students were asked to indicate which HEI they would prefer and the strength of the preference (9point scale).

4. Finally, students were presented with some HEIs and were asked to consider how likely it would be that they would choose each HEI if it was available right now.

\section{Results}

The relative utilities for each attribute level were estimated using the Adaptive Conjoint Analysis software and were then extracted from the ACA software package and analysed further using the SPSS statistical software. Table 2 shows the obtained relative utilities and the relative importance of each of the attributes. 
Table 2. Conjoint analysis results - relative utilities and importance

\begin{tabular}{|c|c|c|c|}
\hline Attribute & Relative Importance (\%) & Level & Average Utility \\
\hline \multirow[t]{3}{*}{ Academic Reputation } & 21 & Has an excellent academic reputation & 104 \\
\hline & & Has a fair academic reputation & 52 \\
\hline & & Has a poor academic reputation & 2 \\
\hline \multirow[t]{2}{*}{ Quality of Facilities } & 19 & Has above average quality of facilities & 97 \\
\hline & & Has average quality of facilities & 2 \\
\hline \multirow[t]{2}{*}{ Job Prospects } & 14 & Would equip with qualifications that provide above average job prospects & 90 \\
\hline & & Would equip with qualifications that provide average job prospects & 1 \\
\hline \multirow[t]{2}{*}{ Campus Atmosphere } & 13 & Has a quiet campus atmosphere & 84 \\
\hline & & Has a lively campus atmosphere & 3 \\
\hline \multirow[t]{2}{*}{ Quality of Teaching } & 11 & Has above average quality of teaching & 79 \\
\hline & & Has average quality of teaching & 2 \\
\hline \multirow[t]{3}{*}{ Distance from Home } & 9 & Is close to home (less than $10 \mathrm{~km}$ ) & 73 \\
\hline & & Is slightly far from home (10-20 km) & 23 \\
\hline & & Is very far from home (over $20 \mathrm{~km}$ ) & 1 \\
\hline \multirow[t]{3}{*}{ Family Opinion } & 7 & Is held in good opinion by family & 69 \\
\hline & & Is a school of which my family holds no opinion & 24 \\
\hline & & Is held in poor opinion by family & 1 \\
\hline \multirow[t]{2}{*}{ Friends } & 6 & Is where my friends will be going & 65 \\
\hline & & Is not where my friends will be going & 2 \\
\hline
\end{tabular}

The average utility scores, shown in column four of Table 2, describe the desirability of the various aspects of an attribute, with higher scores suggesting respondents had a greater preference for that aspect. For example, respondents preferred to attend a school with excellent academic reputation (utility of 104) rather than a school with fair academic reputation (utility of 52). The utility scores not only show the preference 'ranking' but also the degree of preference. For example, the obtained utility scores indicated that respondents preferred to go to a health science and medical HEI that:

1. Has an excellent academic reputation

2. Has above average quality of facilities

3. Would equip with qualifications that provide above average job prospects

4. Has a quiet campus atmosphere

5. Has above average quality of teaching

6. Is close to home (less than $10 \mathrm{~km}$ )

7. Is held in good opinion by family

8. Is where my friends will be going

However, when the utility scores are examined more closely, it can be seen that respondents had greater preference for a health science and medical HEI which provided a strong academic reputation (utility of 104), very good facilities quality (97), good job prospects (90), and a quiet campus atmosphere (84). They had some 
preference for a health science and medical HEI that had a very good teaching quality (utility of 79), that was close to home (73), that the family thought was good (69), and where friends were going (65).

The second column of Table 2 (the relative importance) provides an indication of the importance placed on each attribute relative to the other attributes. Overall, respondents' preferences were determined more by academic reputation (explained $21 \%$ of the range in preferences) than, for example, friends going to the same health science and medical HEI (which explained $6 \%$ of the range in preferences).

The major determinants of health science and medical HEI choice for students in the Philippines and their relative importance are academic reputation (relative importance of $21 \%$ ), quality of facilities (relative importance of 19\%), job prospects (relative importance of 14\%), and campus atmosphere (relative importance of $13 \%)$.

A cluster analysis was undertaken on the utility scores estimated in the conjoint analysis. While the analysis suggested that the best solution was three or four clusters, the point biserial correlations (Peterson and Mahajan, 1976) were only 0.09 and 0.21 respectively, suggesting the sample was homogeneous in its preferences. It appears that there are no useful clusters of prospective students for whom the different attributes included in the conjoint analysis are differentially important. Students seem to develop their preferences in very similar ways implying that marketing strategies need to be generic, rather than targeted.

\section{Conclusions and Implications}

The present study aims to determine the major factors that influence preferences of students who just graduated from senior high school, the relative importance they attach to these factors, and whether there were groups of students for whom different factors were more important. In an attempt to answer the objectives, a conjoint analysis was employed. Based on the analysis, the four most important determinants of health science and medical HEI choice for students in the Philippines are academic reputation, quality of facilities, job prospects, and campus atmosphere. A cluster analysis failed to uncover any useful clusters, suggesting that the sample was relatively homogeneous in their preferences and the trade-offs that they made in developing those preferences.

One of the clearest implications of this research is that health science and medical HEIs that choose to market themselves in terms of the key health science and medical HEI preference determinants are likely to increase their share of preferences. The fact that there no useful clusters identified also has important implications. If a health science and medical HEI does not rate well on the important attributes, it has little to gain by trying to promote itself in terms of some less important attributes. Had there been a segment that considered this attribute to be very important, a health science and medical HEI could market itself to this segment and grow enrolments by increasing its market share of that particular segment. However, there is no segment of students for whom a "low importance attribute" is most important. This means that, for a health science and medical HEI to increase its market share of student preferences, it must be score well on some or all of the four most important attributes (just the strong academic reputation, excellent teaching and facilities quality, and quiet campus atmosphere). 


\section{References}

Alipio, M. M. (2020). Predicting Academic Performance of College Freshmen in the Philippines using Psychological Variables and Expectancy-Value Beliefs to Outcomes-Based Education: A Path Analysis.

Alipio, M. M. (2020). Academic Adjustment and Performance among Filipino Freshmen College Students in the Health Sciences: Does Senior High School Strand Matter.

Cohen, J. W. (1988). Statistical power analysis for the behavioral sciences (2nd edn). Hilldales, NJ: Lawrence Erlbaum Associates, 79-81.

Nasir, A., Noordin, M., Farheeza, D., \& Nordin, M. (2011). Technical skills and non-technical skills: predefinition concept. Proceedings of the IETEC'11 Conference, Kuala Lumpur, Malaysia.

Onega, T., Anderson, M. L., Miglioretti, D. L., Buist, D. S., Geller, B., Bogart, A., ... Yankaskas, B. C. (2013). Establishing a gold standard for test sets: variation in interpretive agreement of expert mammographers. Academic radiology, 20(6), 731-739. doi:10.1016/j.acra.2013.01.012

Shaterjalali, M., Changiz, T., \& Yamani, N. (2018). Optimal clinical setting, tutors, and learning opportunities in medical education: A content analysis. Journal of education and health promotion, 7, 130. doi:10.4103/jehp.jehp_56_18

Yumul, R. (2012). Introduction to Radiologic Technology with Science, Technology and Society (1st ed). Ermita, Manila: Educational Publishing House. 